\title{
Biliary tract invasion and obstruction by hepatocellular carcinoma: report of five cases
}

\author{
S.T. Lai, K.T. Lam ${ }^{1}$ and K.C. Lee \\ Medical B, ${ }^{1}$ Surgical B and ${ }^{2}$ Clinical Pathology Units, Princess Margaret Hospital, Kowloon, Hong Kong
}

\begin{abstract}
Summary: Major biliary tract obstruction caused by tumour invasion is a rare manifestation of hepatocellular carcinoma. The authors had the opportunity to diagnose and treat five such cases, three of whom had features of acute cholangitis. The prevalence of both hepatocellular carcinoma and recurrent pyogenic cholangitis is high in patients from the Far East. The former may first present under the guise of the latter. Gastroenterologists and surgeons should be aware of hepatocellular carcinoma when managing these patients who present with obstructive jaundice, gross hepatomegaly and cholangitis.
\end{abstract}

\section{Introduction}

The authors present five cases of biliary obstruction caused by hepatocellular carcinoma (HCC) invading into the biliary tract. This rare complication of HCC, together with the radiological, operative and pathological findings, is described.

\section{Case reports}

The patients were admitted to Princess Margaret Hospital, Kowloon, Hong Kong between 1988 and 1990. They all presented with jaundice, dark urine, pale stools, epigastric pain, anorexia and weight loss for periods varying from 1 to 6 months. Cases 1, 2 and 4 also had had fever for 1-2 weeks before admission. Other details of the patients are shown in Table I.

Case 2 was admitted to another hospital 2 months previously with complaints similar to those on presentation to us. He had undergone cholecystectomy and exploration of the common bile duct in that hospital. His symptoms then subsided, only to be followed by recurrence 2 months later.

Computerized tomography of the abdomen for cases 1,2, 3 and 5 showed dilated intrahepatic bile ducts and invasion of the common hepatic duct, while masses at the porta hepatis were seen in cases 1,2 and 3 only. Case 4 had marked abdominal pain after admission and an urgent percutaneous transhepatic cholangiogram was done, showing irregular strictures of the right main intrahepatic

Correspondence: S.T. Lai, M.R.C.P.

Accepted: 2 March 1992 duct, common hepatic duct and common bile duct (Figure 1). Percutaneous transhepatic cholangiogram for cases 1 and 3 and endoscopic retrograde cholangio-pancreatography for case 2 (Figure 2) confirmed tumour invasion in the hilar and proximal extrahepatic biliary tract. Hepatic angiogram was performed in case 5 to look for hepatic tumours. A mass with pathological circulation and arterial encasement was found in the right lobe of the liver.

All five patients underwent laparotomy for diagnosis and biliary decompression by external drainage. The hepatic tumours and biliary tract invasion were confirmed at operation. In case 5 , the common bile duct was distended with blood clots. Biopsies of the tumours all revealed hepatocellular carcinoma. In cases 1, 2, 3 and 5 the tumour cells had eosinophilic granular cytoplasm, whereas the cells of case 4 consisted mainly of clear cytoplasm. Bile staining of the tumour parenchyma was not prominent. In two cases residual medium-sized bile ducts were found, which were intimately surrounded by tumour cells. These ducts were dilated containing pale mucoid material.

\section{Discussion}

Hepatocellular carcinoma is a common tumour in the Southern Chinese population of Hong Kong with varied presentations. Hyperbilirubinaemia was detected in $44 \%$ of cases in a large series from Hong Kong. ${ }^{1}$ The causes of jaundice are often due to underlying cirrhosis and/or massive neoplastic infiltration of the liver. However, a small proportion of jaundiced patients, around $2-8 \%,{ }^{2,3}$ have major biliary tract obstruction as a result of 
Table I Features of patients with hepatocellular carcinoma and obstructive jaundice

\begin{tabular}{|c|c|c|c|c|c|c|c|}
\hline $\begin{array}{l}\text { Case } \\
\text { no. }\end{array}$ & $\begin{array}{c}\text { Sex/ } \\
\text { age } \\
\text { (years) }\end{array}$ & $\begin{array}{c}\text { Total } \\
\text { bilirubin } \\
(\mu \mathrm{mol} / \mathrm{l})\end{array}$ & $\begin{array}{c}\text { Alkaline } \\
\text { phosphatase } \\
\text { (IU/l) }\end{array}$ & $A F P$ & $H B s A g$ & $\begin{array}{c}\text { Blood } \\
\text { cultures }\end{array}$ & $\begin{array}{l}\text { Length of } \\
\text { survival after } \\
\text { diagnosis }\end{array}$ \\
\hline 1 & $\mathrm{M} / 58$ & 320 & 500 & - & + & - & 1 month \\
\hline 2 & $\mathrm{M} / 55$ & 183 & 405 & + & + & - & 2 months \\
\hline 3 & $\mathrm{~F} / 54$ & 340 & 180 & + & + & - & 4 months \\
\hline 4 & $\mathbf{M} / 71$ & 490 & 2200 & + & - & $\begin{array}{c}\text { Escherichia } \\
\text { coli }\end{array}$ & 1 week \\
\hline 5 & $M / 65$ & 162 & 240 & + & + & - & $\begin{array}{l}3 \text { months - } \\
\text { bleeding } \\
\text { oesophageal } \\
\text { varices }\end{array}$ \\
\hline
\end{tabular}

$\mathrm{AFP}=$ alpha fetoprotein; $\mathrm{HBsAg}=$ hepatitis $\mathrm{B}$ surface antigen.

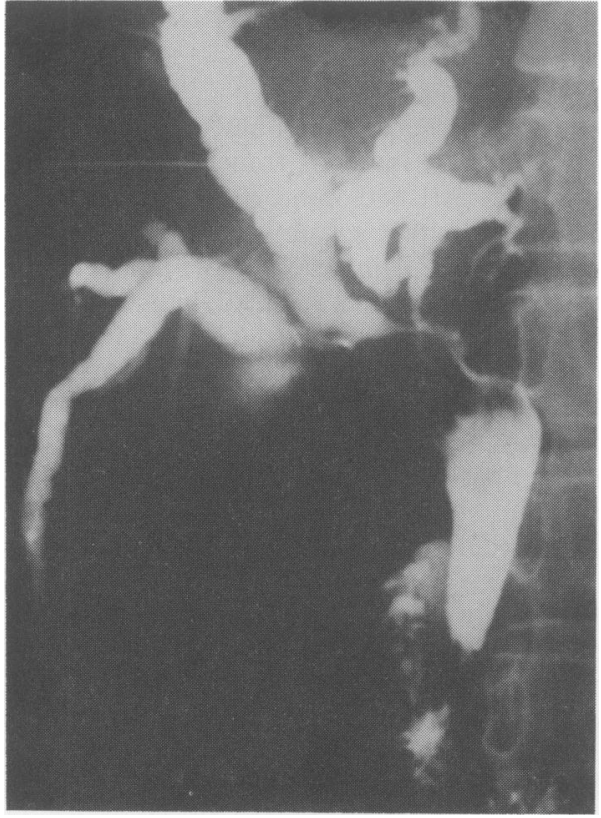

Figure 1 Percutaneous transhepatic cholangiogram showing irregular strictures of the biliary tract.

tumour invasion into the bile ducts, ${ }^{4-9}$ tumour compression, ${ }^{10}$ intrabiliary metastatic tumour polyps $^{11}$ or tumour necrosis with haemobilia..$^{12-13}$ In the patients we have presented, four had tumour invasion and obstruction of the biliary tree - grade III $\mathrm{HCC}^{14}$ while the remainder had blood clots in the common bile duct. It is noteworthy that cases 1 , 2 and 4 presented with Charcot's triad of jaundice, fever and abdominal pain of recent onset, raising the suspicion of cholangitis in these patients. Escherichia coli was actually recovered in the blood

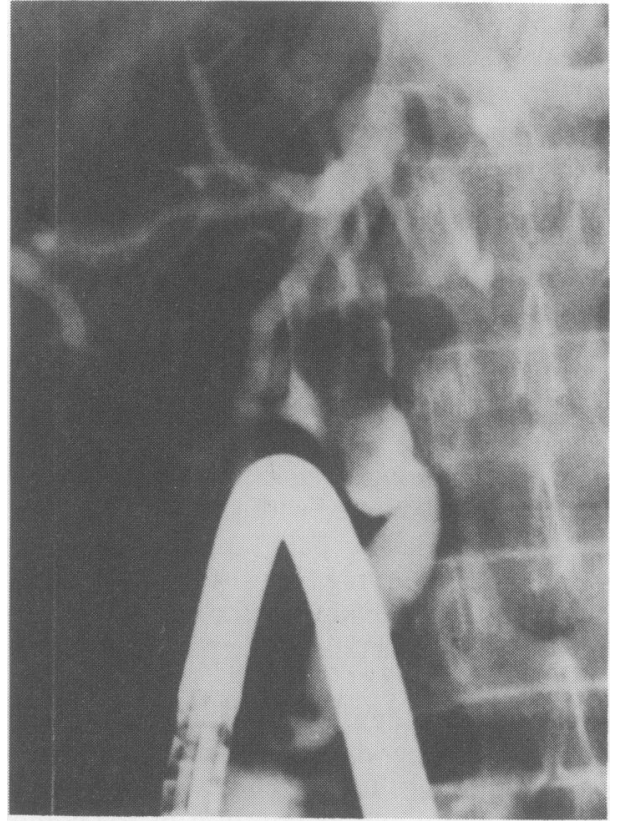

Figure 2 Endoscopic retrograde cholangiopancreatogram showing tumour invasion in the hilar and proximal extrahepatic bile ducts.

in case 4. In the Hong Kong setting, these features are fully compatible with attacks of recurrent pyogenic cholangitis, a common condition in the Far East characterized by recurrent episodes of bacterial cholangitis. ${ }^{15}$

Of the eight clinical forms of HCC proposed by Okuda ${ }^{3}$ the cholestatic type is the rarest. We wish to qualify this entity by adding to it a subgroup presenting with cholangitis, quite indistinguishable from recurrent pyogenic cholangitis initially. No specific pathological features are found to identify 
this subgroup. This is particularly important in the differential diagnoses of acute bacterial cholangitis for patients coming from the Far East. When treating these patients, the attending doctor must bear in mind the possibility of HCC, especially in those with obstructive jaundice and gross hepatomegaly.

The prognosis of HCC invading into major bile ducts has always been grim. ${ }^{4}$ However, there are several reports of curative resection with prolonged survival in the literature ${ }^{16-19}$ probably due to early presentation in obstructing tumours. Therefore, detection of biliary obstruction by $\mathrm{HCC}$ as soon as possible and subsequent radical resection may offer a chance of cure or worthwhile palliation in some patients with this dismal disease.

\section{Acknowledgement}

Thanks are due to Dr H.S. Lam, F.R.C.R., previously of the Radiodiagnostic Unit, Princess Margaret Hospital, for expert radiological opinion.

\section{References}

1. Lai, C.L., Lam, K.C., Wong, K.P., Wu, P.C. \& Todd, D. Clinical features of hepatocellular carcinoma: review of 211 patients in Hong Kong. Cancer 1981, 47: 2746-2755.

2. Ihde, D.C., Sherlock, P., Winawer, S.J. \& Fortner, J.G. Clinical manifestations of hepatoma. A review of 6 years' experience at a cancer hospital. Am J Med 1974, 56: 83-91.

3. Okuda, K. Clinical aspects of hepatocellular carcinoma analysis of 134 cases. In: Okuda, K. \& Peters, R.L. (ed.) Hepatocellular Carcinoma. John Wiley, New York, 1976, pp. 387-436.

4. Wind, G. \& Futterman, S. Obstructive jaundice secondary to hepatoma. Case report and literature review. Am J Gastroenterol 1977, 67: 80-83.

5. Sonnenberg, E.V. \& Ferrucci, J.T. Bile duct obstruction inhepatocellular carcinoma (hepatoma) - clinical and cholangiographic characteristics. Radiology 1979, 130: 7-13.

6. Kojiro, M., Kawabata, K., Kawano, Y., Shirai, F., Takemoto, N. \& Nakashima, T. Hepatocellular carcinoma presenting as intrabile duct tumor growth. A clinicopathologic study of 24 cases. Cancer 1982, 49: 2144-2177.

7. Joehl, R.J. \& Abt, A.B. Obstructive jaundice caused by hepatocellular carcinoma. J Surg Oncol 1984, 27: 80-84.

8. Mooser, M.R., Segal, I., Mannell, A., Hodkinson, J.H. \& Paterson, A. Bile duct obstruction in hepatocellular carcinoma - visualization by endoscopic retrograde cholangiogram. A case report. $S$ Afr Med J 1984, 66: 962-964.

9. Kiev, J., Dyslin, D.C., Vitenas, P. \& Kerstein, M.D. Obstructive jaundice caused by hepatoma fragments in the common hepatic duct. J Clin Gastroenterol 1990, 12: 207-213.

10. Lee, K.C., Sakai, K., Kinoshita, H. et al. Resection of hepatocellular carcinoma with obstructive jaundice caused by compression of the common hepatic duct. J Surg Oncol 1988, 39: 201-205.
11. Terada, T., Nakanuma, Y. \& Kawai, K. Small hepatocellular carcinoma presenting as intrabiliary pedunculated polyp and obstructive jaundice. J Clin Gastroenterol 1989, 11: 578-583.

12. Brand, S.N., Brandt, L.J., Sprayregan, S., Brenner, S. \& Bernstein, L.H. Extrahepatic biliary tract obstruction secondary to a hepatoma-containing blood clot in the common bile duct. Am J Dig Dis 1976, 21: 905-909.

13. Rhoe, B.S., Kim, H., Jin, S.Y. \& Jang, W.I. Hepatoma presenting as extrahepatic biliary obstruction due to hemobilia. Yonsei Med J 1989, 30: 383-386.

14. Edmondson, H.A. \& Steiner, P.E. Primary carcinoma of the liver. A study of 100 cases among 48,900 necropsies. Cancer 1954, 7: 462-503.

15. Lam, S.K., Wong, K.P., Chan, P.K.W., Ngan, H \& Ong, G.B. Recurrent pyogenic cholangitis: a study by endoscopic retrograde cholangiography. Gastroenterology 1978, 74: 1196-1203.

16. Lee, N.W., Wong, K.P., Siu, K.F. \& Wong, J. Cholangiography in hepatocellular carcinoma with obstructive jaundice. Clin Radiol 1984, 35: 119-123.

17. Kuroyanagi, Y., Sawada, M., Hidemura, R., Aoki, S. \& Kato, H. Common bile duct obstruction by hepatoma. Am J Surg 1977, 133: 233-235.

18. Tsuzuki, T., Ogata, Y., Iida, S., Kasajima, M. \& Takahashi, S. Hepatoma with obstructive jaundice due to migration of a tumor mass in the biliary tract: report of a successful resection. Surgery 1979, 85: 593-598.

19. Lau, W.Y., Leung, J.W.C. \& Li, A.K.C. Management of hepatocellular carcinoma presenting as obstructive jaundice. Am Surg 1990, 160: 280-282. 